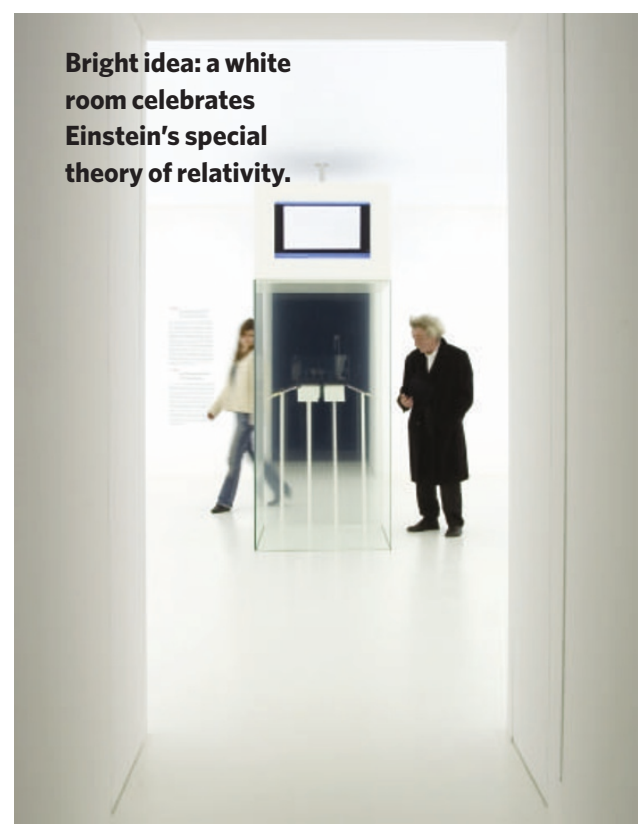

it deserves will note Einstein's opening, gently teasing, gambit to Newton: "I had the honour of standing on your shoulders and thus being able to see a little further". Einstein also stood on the more modern German shoulders of Boltzmann, Planck and Ernst Mach. But Einstein, so the exhibition tells us, belongs to international science - and this shaper of space-time was shaped by his own space and time.

Alison Abbott is Nature's senior European correspondent.

\section{A braver, newer world}

\author{
Never Let Me Go \\ Kazuo Ishiguro \\ Faber and Faber/Alfred Knopf: 2005. \\ 263 pp. $€ 16.99 / \$ 24$
}

\section{Justine Burley}

Never Let Me Go is a literary tour de force and the finest expression of moral disquietude over advances in the biomedical science since Aldhous Huxley's Brave New World more than 70 years ago. Whereas Huxley's dystopia is central to his story, in Kazuo Ishiguro's tale the dystopic social order provides menace from the background. There are, however, notable likenesses between the two books. In both, the characters are bred and educated to fulfil predestined roles. In both, the changes that have been wrought by science on our moral landscape are traceable to bald utilitarian reasoning. And in both, a misguided notion of progress is laid bare by juxtaposing an existing world against an alternative future one.

Whereas the title of Brave New World dangles the lure of progress, with sardonic wit, the title of Never Let Me Go beseeches us to cling tightly to our current values. It is no accident that Ishiguro's book is set in the 1990s when the birth of Dolly the cloned sheep was announced and the human genome project was well under way. Both developments prompted debate over what limits

\section{MORE ON EINSTEIN}

Here is a selection of the new and reissued books about Einstein published this year to celebrate the World Year of Physics.

For those who wish to read the five papers that Einstein produced in 1905, Einstein's Miraculous Year edited by John Stachel (Princeton University Press, $\$ 16.95, £ 10.95$ ) is a good place to start. This new version contains a foreword by Roger Penrose and a new introduction by John Stachel examining Einstein's early life, leading up to the writing of these famous papers.

Alice Calaprice, author of The Quotable Einstein, has now produced The Einstein Almanac (Johns Hopkins University Press, $\$ 24.95, £ 17$ ), a chronological listing of 300 of Einstein's publications spanning the years from 1901 to 1955 . These are interspersed with biographic details and other notable news from the world of physics. This is a useful book for Einstein enthusiasts to dip into. Examples of Einstein's more popular writings can be found in the reissued Ideas and Opinions (Souvenir Press, E9.99).

For those seeking to understand the significance of Einstein's papers, Nigel Calder's Einstein's Universe (Penguin, $€ 7.99, \$ 14$ ) has been reissued. Einstein's Cosmos by Michio Kaku (W. W. Norton, \$13.95) examines how Einstein's vision transformed our understanding of space and time. A second edition of David C. Cassidy's Einstein and Our World (Humanity Books, \$21) places Einstein's work in its scientific and wider cultural context.

Einstein: A Life in Science by Michael White and John Gribbin (Free Press, $€ 7.99$ ), a short biography, makes a reappearance, along with another offering by John Gribbin, this time with Mary Gribbin, Annus Mirabilis (Penguin/Chamberlain Bros, \$25.95). This brief biography also includes a reproduction of Einstein's own book Relativity: The Special and General Theory, first published in 1916, and a DVD of the A\&E biography of Einstein.

Reviews of other Einstein books appeared in the 20 January issue of Nature (433, 195-197; 2005). should be placed on applications of related technologies. The prospect of having detailed control over the sort of people who come to exist made many uneasy. For the first time since Darwin's theory of evolution took the world by storm, people sensed that our ethical parameters might be starting to shift. In Never Let $\mathrm{Me} G o$, such a shift has occurred: the maxim that individuals should never be treated solely as a means to the ends of others is outmoded.

The few facts we pick up about how this transition occurred, and about the complexion of the resulting society, are revealed gradually, in the telling of a life. The narrator is Kathy, a carer who is soon to be "retired". Her two friends, Tommy and Ruth, have already "completed" following their "donations". Kathy's reminiscences of their intertwined lives return time and again to their cloistered upbringing at a boarding school called Hailsham, unveiling in the process the appalling fate for which it prepared them. The most powerful aspect of the story is the author's intensely controlled psychological portrait of these three individuals, rather than the raw facts about the system that oppressed them.

Much attention is paid to banalities minutely observed: a sports pavilion, an incident involving a lost pencil case, and isolated acts of tomfoolery. These preoccupations of memory strike the reader as being at once utterly normal and utterly incomprehensible. It is as necessary to this book as it was to Ishiguro's The Remains of the Day that we have a detailed insight into how his characters see the world and yet never manage to grasp quite how they can see it thus. This imposed distance between reader and subject serves to force a confrontation with big questions about human identity and all that shapes our values, the temptations of science and technology included.

The only coercive force ever named in the book is 'society'. Misuse of technology in the name of the common good is by no means a novel theme. Unique to Ishiguro's treatment of it is his carefully layered picture of the way in which the principal characters forge and retain their individuality in circumstances designed to deny them any importance as individuals. What most chills the reader is not the cold reality they face, it is that they have internalized it and made it a part of who they are.

Never Let Me Go ought to win every major literary award this year. It captures so very beautifully the importance of what we care about.

Justine Burley is at the Graduate School for the Integrative Sciences and Engineering, National University of Singapore, MD 11, \#01-10, 10 Medical Drive, 117597, Singapore. 